\title{
Changing refractive outcomes with increasing astigmatism at longer-term follow- up for infant cataract surgery
}

\begin{abstract}
Purpose To present longer-term refractive and ocular health outcomes for patients who had primary intraocular lens (IOL) insertion following infant cataract surgery. Patients and methods A retrospective review of all infant cataract cases at a tertiary children's hospital between 2003 and 2006 was conducted. Surgery was performed before 12 months of age. IOL power was calculated using the SRK/T formula targeting hyperopia based on the child's age; children under 3 months were targeted at $+9.0 \mathrm{D}$, between 3 and 6 months at $+6.0 \mathrm{D}$, and between 6 and 12 months at $+3.0 \mathrm{D}$. Locally weighted scatterplot smoothing and mixed models were used.

Results A total of 12 eyes from 9 children were included (4 bilateral and 5 unilateral). Spherical equivalent refraction decreased dramatically in the first 2 years of life, with milder changes from age 2 to 4 years and minimal changes thereafter. Cylinder increased until age 5 years at $\sim 0.57$ dioptres/ year $(95 \%$ confidence intervals $0.27-0.87 \mathrm{D}$, $P<0.001)$. Lens reproliferation was the commonest complication (58\%). All children eventually developed strabismus. Conclusion Early and frequent refraction is critical in the first 2 years of life to try and compensate for the rapid changes encountered in the growing eye. Astigmatism may be another important consequence to manage. Eye (2016) 30, 1195-1198; doi:10.1038/eye.2016.147; published online 15 July 2016
\end{abstract}

\section{Introduction}

Intraocular lens (IOL) insertion after infant cataract surgery has been an area of much discussion. The Infant Aphakic Treatment Study (IATS) ${ }^{1,2}$ has
C Samarawickrama ${ }^{1,2}$, Y-C Li ${ }^{2}$, N Kanapathipillai ${ }^{2}$ and JR Grigg ${ }^{1,2,3}$

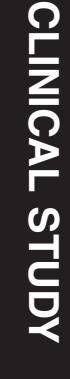

provided some answers to this complex problem for the first 5 years. Clinicians must rely on observational case series to try to elucidate the longer-term outcomes of their treatment paradigms beyond 5 years. We present our refractive and ocular health outcomes from a single surgeon series of 12 eyes where primary IOL implantation was performed.

\section{Materials and methods}

A retrospective review of all cases under 12 months of age who underwent cataract extraction by a single surgeon (JRG) between November 2003 and December 2006 at a tertiary referral pediatric hospital was performed. Ethics approval was obtained from the Children's Hospital at Westmead.

Under general anesthesia, an anterior chamber maintainer with balanced salt solution, added sodium heparin 1 unit $/ \mathrm{ml}$, and adrenaline $0.5 \mathrm{ml}$ was used. The surgical steps were: superior corneal $3.5 \mathrm{~mm}$ incision, Trypan blue-assisted capsulorexhus ('push-pull' technique ${ }^{3}$ ), hydrodissection, lens aspiration, and 3-piece hydrophobic acrylic lens (MA60AC; Alcon, Fort Worth, TX, USA) with PMMA haptics implanted in the capsular bag. A primary posterior capsulotomy with limited anterior vitrectomy was performed under the IOL. Wounds were closed with 10-0 vicryl. Finally, a subtenons/ subconjunctival injection of Marcaine, cepholothin $125 \mathrm{mg}$, and dexamethasone $2 \mathrm{mg}$ was instilled.

Postoperative regime was chloramphenicol and prednisolone acetate $1 \%$ with phenylephrine hydrochloride $0.12 \%$ (Predneferin Forte, Allergan, Parsippany-Troy Hills, NJ, USA) q.d.s. Those with bilateral cataracts had contralateral surgery within 3 weeks.
${ }^{1}$ Sydney Eye Hospital, Sydney, New South Wales, Australia

${ }^{2}$ Save Sight Institute, Sydney Medical School, University of Sydney, Sydney, New South Wales, Australia

${ }^{3}$ The Children's Hospital at Westmead, Westmead, New South Wales, Australia

Correspondence:

C Samarawickrama, Sydney Eye Hospital, 8 Macquarie Street, Sydney New South Wales 2000, Australia Tel: +61 293827111 ; Fax: +61 293827111 E-mail: chameensams@ gmail.com

Received: 21 January 2016 Accepted in revised form:

7 June 2016

Published online:

15 July 2016 
Intraoperative biometry with A-Scan and hand-held keratometry using the SRK/T formula was performed. Target refraction was selected based on age: children $\leqslant 3$ months old were targeted at $+9.0 \mathrm{D}$, those between 3 and 6 months at $+6.0 \mathrm{D}$, and those between 6 and 12 months at $+3.0 \mathrm{D}$.

Statistical analysis was performed with SPSS software (Chicago, IL, USA). Locally weighted scatterplot smoothing (LOESS) and mixed models were created to analyse the association between age and spherical equivalent refraction (SER; $\mathrm{SER}=$ sphere $+\frac{1}{2}$ cylinder) and cylinder.

\section{Results}

Nine patients met the age and entry criteria (Table 1). All patients were systemically well. One child had developmental delay and mild dysmorphic features. All patients required either spectacle or contact lenses for correction of their residual refractive errors.

\section{Refractive outcomes}

Figure 1 demonstrates the change in SER over time for (Figure 1a) unilateral and (Figure 1b) bilateral cases. In both groups, the most dramatic change occurred within the first 2 years of life, followed by a milder change from age 2-4 years and minimal changes thereafter.

We observed an increase in astigmatism with time (Figure 2a for unilateral cases and Figure 2b for bilateral cases). Across both unilateral and bilateral cases, the most rapid change occurred before age 5 (mean change of $0.57 \mathrm{D}$ per year, $95 \%$ confidence intervals $0.27-0.87 \mathrm{D}$, $P<0.001)$ that tended to stabilize afterwards $(P=0.1)$.

\section{Ocular health outcomes}

One sulcus IOL positioning was required because of an adherent cataract-capsule complex. Glaucoma occurred in one child requiring treatment. All other children maintained an IOP below $22 \mathrm{~mm} \mathrm{Hg}$.

Lens reproliferation was seen in 7 of 12 eyes (58\%) managed with YAG laser.

Two late ocular complications occurred including one dislocated IOL after a fall. A separate unilateral cataract patient developed a choroidal new vessel 4.5 years after cataract surgery, with no clear cause identified.

All children developed strabismus over time manifesting as six exotropias and three esotropias. Nystagmus occurred in three patients.

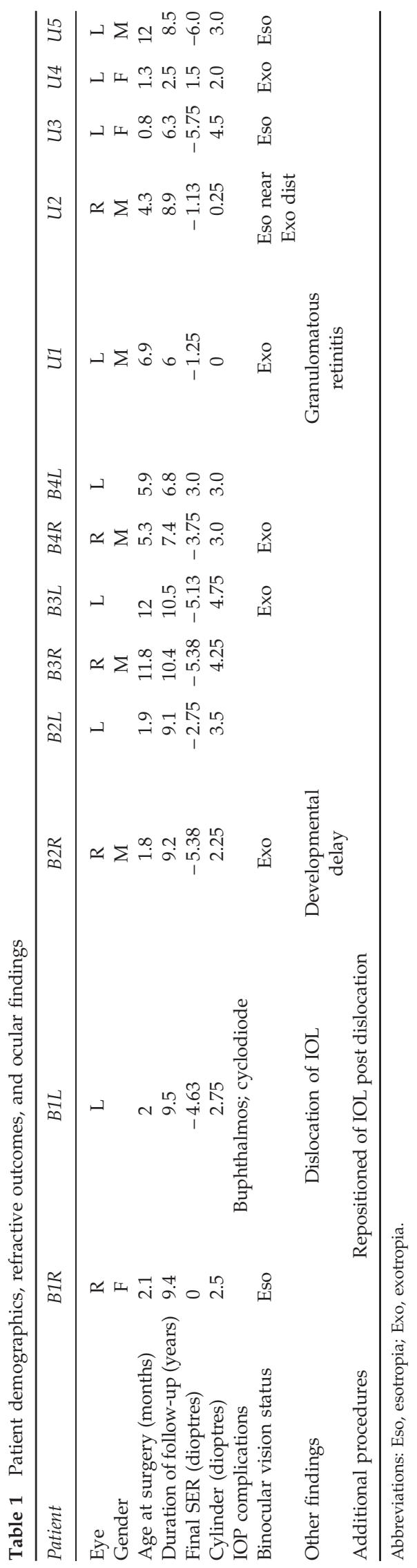


Longer-term outcomes from infant cataract surgery

C Samarawickrama et al

1197

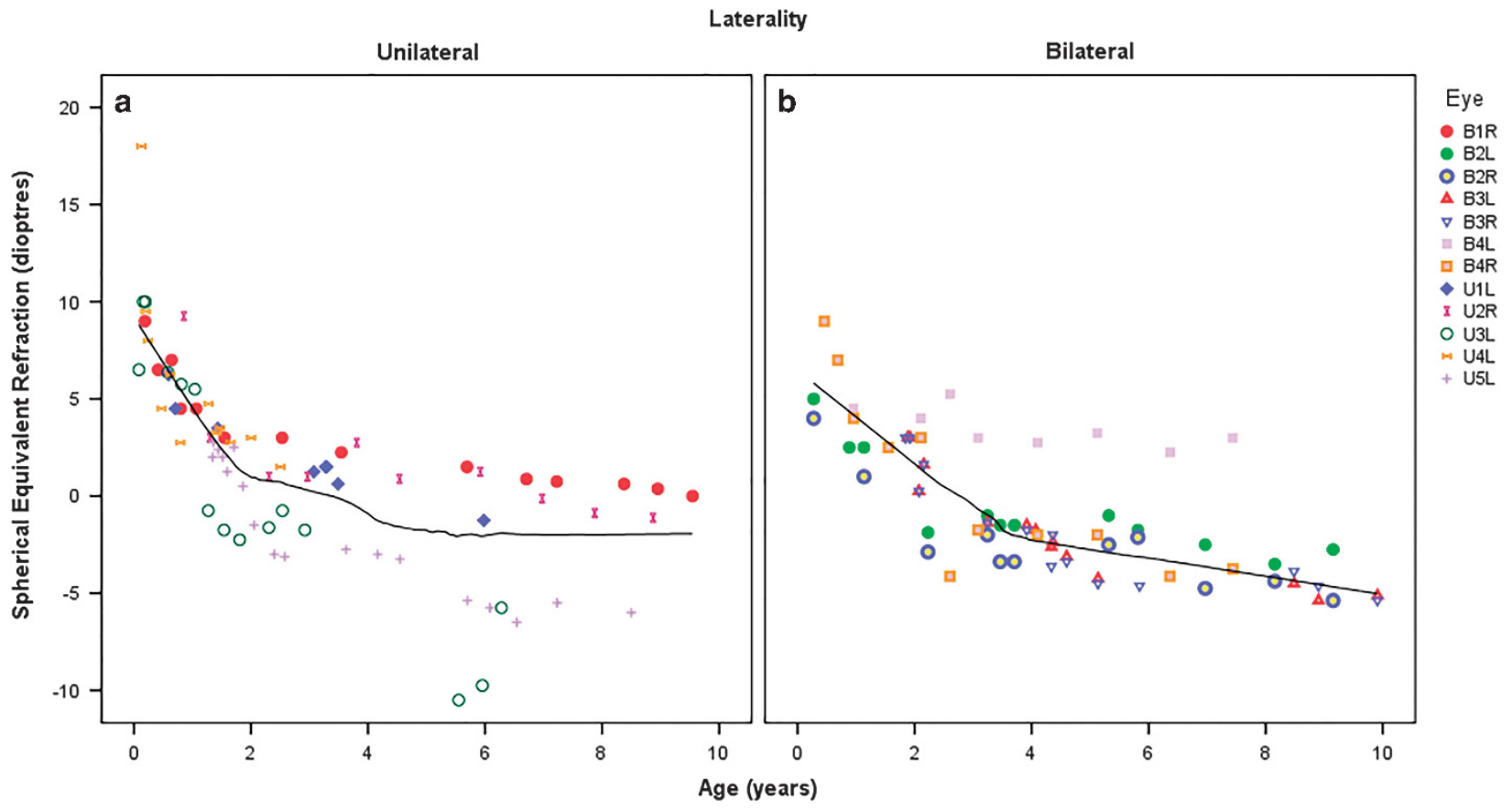

Figure 1 Change in spherical equivalent refraction (SER) over time in (a) unilateral and (b) bilateral infant cataract patients. A locally weighted scatterplot smoothing (LOESS) line demonstrates the mean decrease in SER over time. The most dramatic change in SER occurs in the first 2 years of life, with a mild change from age 2 to 4 years and minimal changes thereafter.

Laterality

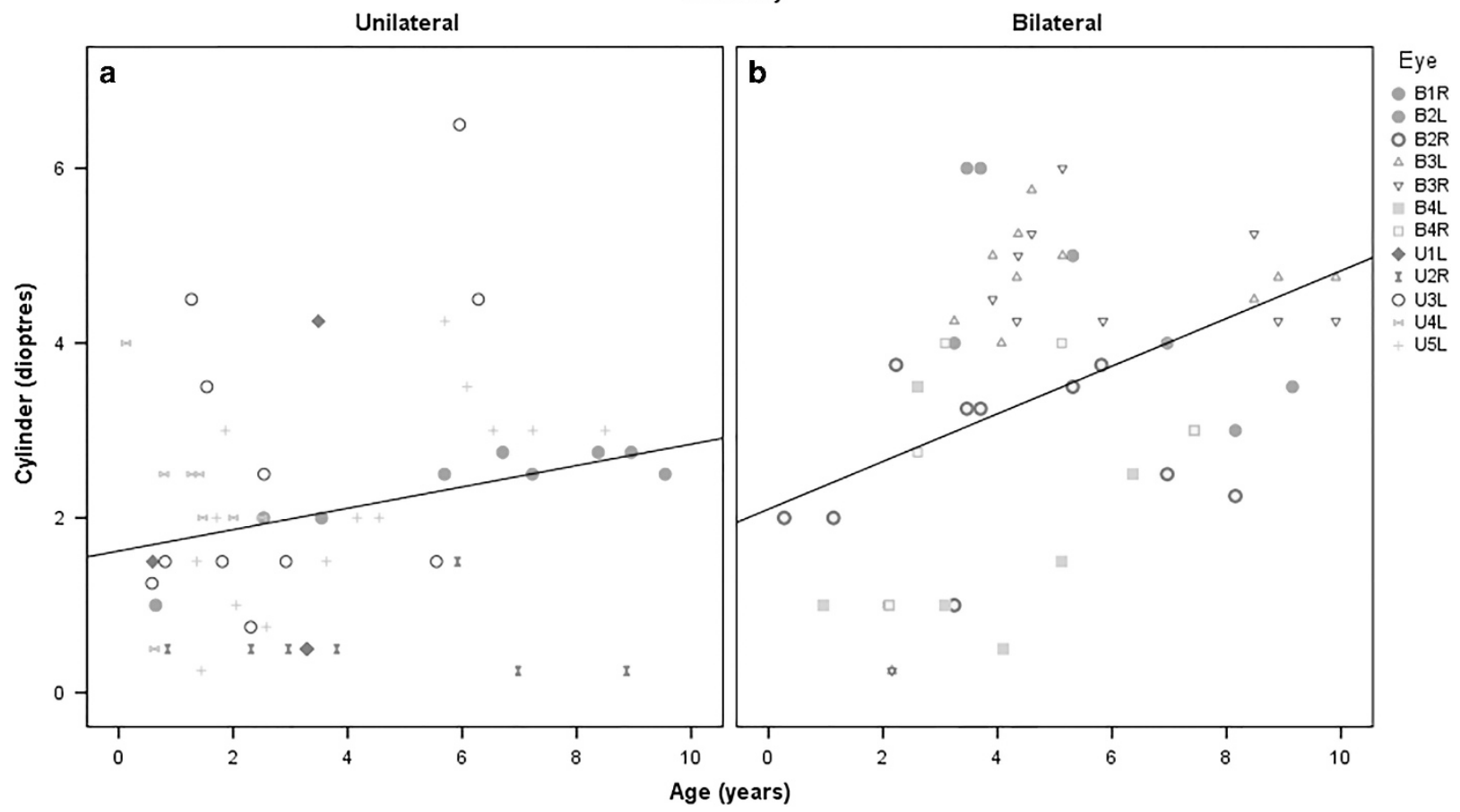

Figure 2 Change in astigmatism with time in (a) unilateral and (b) bilateral infant cataract patients. All patients except one had an increase in cylinder with time. A line of best fit demonstrates the trend $(P<0.001)$.

Eye 


\section{Discussion}

The changes in SER seen in our study reflects the rapid growth in axial length within the first 2 years of life. ${ }^{4-9}$ The critical message from our study is that there is a rapid change in refraction in the first 2 years that declines over the following 2 years and tends to stabilize by age 4 years. This implies that frequent refraction and change of glasses/contact lenses are needed in the first 2 years, followed by regular checks (at least 6 monthly) from age 2 to 4 years. Annual refraction checks in stable patients is likely adequate after age 4 years.

Lens reproliferation was the most frequent long-term complication encountered, in keeping with the literature. ${ }^{1,2,10-12}$ Only a single case of high IOP was encountered. The strabismus rate is higher than previously reported ${ }^{12,13}$ but may be reflective of the longer follow-up.

Interestingly, we found an increase in astigmatism with time that has not been reported in the literature. We have no keratometry data available. One theory is the PMMA haptics of the IOL may exert a stretching force on the pliant tissue of the infant eye inducing astigmatism that stabilizes as the scleral rigidity increases. A further conjecture is that the human lens plays an important role in ocular development and an IOL may not balance the cornea leading to astigmatism. Finally, it may be that the results are artificial because of the small numbers. Further studies are needed to explore this finding.

\section{Summary}

What was known before

- The decision to insert an IOL after infant cataract surgery is an area of much contention. The IATS demonstrated in unilateral cataracts a benefit in leaving the eye aphakic in terms of complications and adverse events. However, it also acknowledged that longer-term results may change the benefit profile in favour of the primary IOL group.

- No longer-term data beyond 7-year results are available in either group.

\section{What this study adds}

- First report of longer-term outcomes of both unilateral and bilateral pediatric cataract surgery with primary IOL implantation.

- Spherical equivalent refraction decreased primarily in the first 2 years and then tended to plateau.

- Cylinder increased until age 5 years.

- All children developed strabismus.

\section{Conflict of interest}

The authors declare no conflict of interest.

\section{References}

1 Infant Aphakia Treatment Study Group, Lambert SR, Lynn MJ, Hartmann EE, DuBois L, Drews-Botsch C et al. Comparison of contact lens and intraocular lens correction of monocular aphakia during infancy: a randomized clinical trial of HOTV optotype acuity at age 4.5 years and clinical findings at age 5 years. JAMA Ophthalmol 2014; 132: 676-682.

2 Plager DA, Lynn MJ, Buckley EG, Wilson ME, Lambert SR, Infant Aphakia Treatment Study Group. Complications in the first 5 years following cataract surgery in infants with and without intraocular lens implantation in the Infant Aphakia Treatment Study. Am J Ophthalmol 2014; 158: 892-898.

3 Nischal KK. Two-incision push-pull capsulorhexis for pediatric cataract surgery. J Cataract Refract Surg 2002; 28: 593-595.

4 Fledelius HC, Christensen AC. Reappraisal of the human ocular growth curve in fetal life, infancy, and early childhood. Br J Ophthalmol 1996; 80: 918-921.

5 Flitcroft DI, Knight-Nanan D, Bowell R, Lanigan B, O'Keefe M. Intraocular lenses in children: changes in axial length, corneal curvature, and refraction. $\mathrm{Br} J$ Ophthalmol 1999; 83: 265-269.

6 Crouch ER, Crouch Jr ER, Pressman SH. Prospective analysis of pediatric pseudophakia: myopic shift and postoperative outcomes. J AAPOS 2002; 6: 277-282.

7 McClatchey SK, Parks MM. Myopic shift after cataract removal in childhood. J Pediatr Ophthalmol Strabismus 1997; 34: 88-95.

8 Walker RA, Romanchuk KG. Long-term refractive change after intraocular lens implantation in childhood. Can J Ophthalmol 2006; 41: 464-468.

9 Hoevenaars NE, Polling JR, Wolfs RC. Prediction error and myopic shift after intraocular lens implantation in paediatric cataract patients. Br J Ophthalmol 2011; 95: 1082-1085.

10 Lundvall A, Zetterstrom C. Primary intraocular lens implantation in infants: complications and visual results. J Cataract Refract Surg 2006; 32: 1672-1677.

11 Astle WF, Alewenah O, Ingram AD, Paszuk A. Surgical outcomes of primary foldable intraocular lens implantation in children: understanding posterior opacification and the absense of glaucoma. J Cataract Refract Surg 2009; 35: 1216-1222.

12 Struck MC. Long-term results of pediatric cataract surgery and primary intraocular lens implantation from 7 to 22 months of life. JAMA Ophthalmol 2015; 133: 1180-1183.

13 Autrata R, Rehurek J, Vodickova K. Visual results after primary intraocular lens implantation or contact lens correction for aphakia in the first year of age. Ophthalmologica 2005; 219: 72-79. 